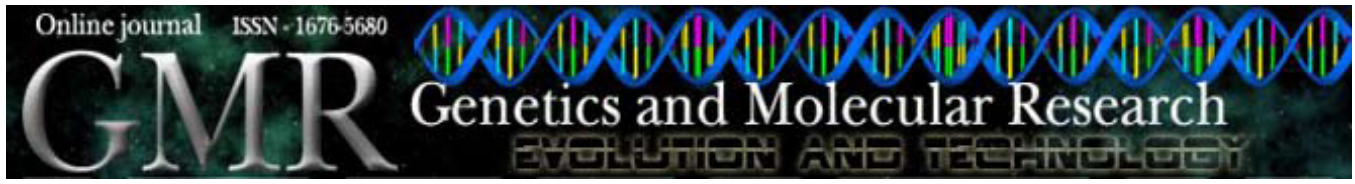

\title{
Molecular markers in commercial Bombyx mori (Lepidoptera: Bombycidae) hybrids susceptible to multiple nucleopolyhedrovirus
}

\author{
L.F.C. Ribeiro ${ }^{1,2}$, D.B. Zanatta ${ }^{1}$, J.P. Bravo ${ }^{1}$, R.M.C. Brancalhão ${ }^{2}$ and \\ M.A. Fernandez ${ }^{1}$ \\ ${ }^{1}$ Departamento de Biologia Celular e Genética, \\ Laboratório de Organização Funcional do Núcleo, \\ Universidade Estadual de Maringá, Maringá, PR, Brasil \\ ${ }^{2}$ Departamento de Ciências Biológicas e da Saúde, \\ Laboratório de Biologia Celular e Microtécnica, \\ Universidade Estadual do Oeste do Paraná, Cascavel, PR, Brasil \\ Corresponding author: M.A. Fernandez \\ E-mail: aparecidafernandez@gmail.com
}

Genet. Mol. Res. 8 (1): 144-153 (2009)

Received October 20, 2008

Accepted November 24, 2008

Published February 17, 2009

\begin{abstract}
The silkworm Bombyx mori L. is particularly susceptible to virus diseases, especially B. mori nucleopolyhedrovirus (BmNPV). Disease resistance, along with high productivity, are important selection criteria for developing commercial hybrids of $B$. mori. We used bioassays and molecular markers linked to susceptibility/resistance to baculovirus infection to analyze the response of commercial $B$. mori hybrids from two companies to a geographic isolate of $B$. mori multiple nucleopolyhedrovirus (BmMNPV) from Paraná State in Brazil. Both of these commercial lines were highly susceptible to BmMNPV, with death rates of 92 and $94 \%$. A polymorphic fragment of approximately $\sim 350 \mathrm{bp}$, associated with susceptibility, and an $\sim 800$-bp fragment, associated with resistance to BmMNPV, were detected in all specimens. An additional fragment of
\end{abstract}


$\sim 480 \mathrm{bp}$, recently identified by our research team as a BmMNPV genomic sequence, was detected in the infected silkworms and could be used as a molecular marker for the diagnosis of nucleopolyhedrovirus infection.

Key words: Silkworm; Bombyx mori multiple nucleopolyhedrovirus; Molecular markers; Random amplified polymorphic DNA;

Polymorphism

\section{INTRODUCTION}

Bombyx mori L. (silkworm) diseases cause great economic losses to sericulture, an important agricultural activity in Brazil and the world. The silkworm nucleopolyhedrovirus (BmNPV) is a highly infective virus and one of the most important virus diseases causing larval death. BmNPV is a member of the Baculoviridae family and has an enveloped, circular and double-stranded DNA of $130 \mathrm{kbp}$, associated with a protein capsid, which forms the nucleocapsid (Barrett et al., 1998).

Nucleopolyhedroviruses have two distinct morphological forms: the budded virus, causing cell-by-cell systemic infection in the insect, consists of a single-enveloped nucleocapsid, the polyhedral-derived virus comprises multiple nucleocapsids occluded in a crystalline matrix mainly composed of polyhedron protein. The latter causes the horizontal transmission of the disease, insect to insect, after being ingested by the host (Zhou et al., 2005). NPV is polyorganotrophic, and several tissues have been pinpointed as specific targets of infection (Adams and McClintock, 1991; Brancalhão et al., 2002; Torquato et al., 2006; Pereira et al., 2008).

Brancalhão (2002) recovered from B. mori larvae a geographic NPV isolate in the State of Paraná, Brazil, characterized as a B. mori multiple nucleopolyhedrovirus (BmMNPV). The state accounts for $90 \%$ of the Brazilian production of green cocoons, and this isolate belongs to a multiple subgroup, which is a more virulent genotype due to the high rate of nucleocapsids per envelope (Zhou et al., 2005).

B. mori silkworm strains differ considerably with respect to BmNPV resistance. It is controlled by the activity of many genes, which produce proteases and lipases present in $B$. mori gastric juice, against the viral infection (Ponnuvel et al., 2003; Nakazawa et al., 2004). Polygenic control detects dominant genes and multiple micro-effector genes, which makes the understanding of the inheritance of resistance to BmNPV very difficult (Goldsmith et al., 2005). Studies on B. mori polymorphism will be of importance in genetic improvement programs for the characterization of pure strains and their hybrids and for obtaining an elite hybrid that would have the best traits for production and survival (Fernandez et al., 2005). B. mori genetic polymorphism has been detected by several molecular markers. In fact, the mapping of its genome has revealed inheritance pattern (homozygous and heterozygous), and the genetic distance between the several strains cultivated worldwide (Goldsmith et al., 2005).

Random amplified polymorphic DNA (RAPD) markers are the most important among molecular markers (Williams et al., 1990) since they reveal DNA polymorphisms among genetically related individuals. RAPD markers in loci $n s d-1$ (Abe et al., 1995) and $n s d-2$ (Abe et al., 2000) have been related to the silkworm's resistance to densonucleosis virus. A similar strategy has been used to identify the NPV, another important silkworm genotype virus (Yao et al., 2003). 
The present study examined the biological response of commercial B. mori hybrids from two companies in Brazil when submitted to inoculation with BmMNPV and determined the molecular markers associated with virus resistance and/or susceptibility in these silkworms.

\section{MATERIAL AND METHODS}

\section{Commercial hybrids of Bombyx mori}

Commercial hybrids at the third instar of development were obtained from two companies (Co.A and Co.B), which commercialize the silkworm in the State of Paraná, Brazil. Larvae from each company were divided into two groups: one group was inoculated with BmMNPV and the other was the control. Silkworms were raised until the end of their life cycle and fed three times a day with fresh mulberry leaves (Morus sp).

\section{Biological assay}

Since $B$. mori susceptibility to pathogens may be affected by several external factors (Sengupta et al., 1990), parameters proper to normal development on the silkworm farms were maintained during silkworm breeding in the laboratory. BmMNPV inoculum was obtained from previously infected B. mori larvae (Brancalhão et al., 2000), and viral suspension was 1.4 x $10^{6}$ polyhedral occlusion bodies $/ \mathrm{mL}$. The experiments were carried out with 50 silkworms of the fifth instar larval, and for each group (Co.A and Co.B) the inoculation was carried out $24 \mathrm{~h}$ after ecdysis. They were fed on mulberry leaf discs $(2 \mathrm{~cm}$ in diameter) previously sprayed with BmMNPV viral suspension, whereas the silkworms of the control group were fed on mulberry leaf discs sprayed with filtered water.

\section{DNA extraction}

DNA was extracted from a pair of silk glands from five control and five BmMNPVinoculated larvae, from the two groups, dissected on the seventh day postinoculation (dpi) and previously stored in absolute isopropyl alcohol at $-20^{\circ} \mathrm{C}$. The protocol for genomic DNA extraction was followed as described by Monesi et al. (1998), with modifications. Briefly, a pair of silk glands was solubilized in $1 \mathrm{~mL}$ extraction buffer $(50 \mathrm{mM}$ Tris- $\mathrm{HCl}, \mathrm{pH} 8.0,5 \mathrm{mM}$ EDTA, $\mathrm{pH} 8.0 ; 1.5 \%$ sarcosyl, $10 \mathrm{mM} \mathrm{NaCl}$, and $1.0 \mathrm{mg} / \mathrm{mL}$ proteinase $\mathrm{K}$ ) at $60^{\circ} \mathrm{C}$ for $3 \mathrm{~h}$. Biological material was then purified with an equal volume of phenol, $\mathrm{pH} 8.0$, and phenol/ chloroform, precipitated with ethanol and resuspended in TE $(10 \mathrm{mM}$ Tris-HCl, $\mathrm{pH} 8.0$, and 1 mM EDTA, $\mathrm{pH} 8.0)$ with RNase A $(50 \mu \mathrm{g} / \mathrm{mL})$ (Invitrogen).

\section{Obtaining susceptibility and resistance bands by RAPD}

Primers OPA-18 (5'-AGGTGACCGT-3') and OPY-11 (5'-CTGATGCGTG-3'), Operon Technologies, described by Yao et al. (2003), were used to obtain the RAPD profile of the commercial hybrids as marker linked to resistance and susceptibility to the NPV, respectively.

Amplification by polymerase chain reaction was undertaken in a reaction mixture with $20 \mu \mathrm{L}$ as a final volume comprising $10 \mathrm{X}$ buffer Taq polymerase $(20 \mathrm{mM}$ Tris- $\mathrm{HCl}, \mathrm{pH}$ 
8.0, $0.1 \mathrm{mM}$ EDTA, $1 \mathrm{mM}$ DTT, 50\% (v/v) glycerol, as stabilizers) (Invitrogen), $0.75 \mathrm{mM}$ $\mathrm{MgCl}_{2}, 200 \mu \mathrm{M}$ dNTPs and $1.25 \mu \mathrm{M}$ primer, $1 \mathrm{U}$ Taq DNA polymerase (Invitrogen) and 20 ng genomic DNA. The reaction was carried out under the following conditions: 38 cycles and a final extension of $72^{\circ} \mathrm{C}$ for $10 \mathrm{~min}$. Each cycle consisted of denaturation at $94^{\circ} \mathrm{C}$ for 30 $\mathrm{s}, 38^{\circ} \mathrm{C}$ for $60 \mathrm{~s}$ and $72^{\circ} \mathrm{C}$ for $120 \mathrm{~s}$. Polymerase chain reaction products were visualized on $1.5 \%$ agarose gels or on $6 \%$ polyacrylamide gels. Polyacrylamide gels were pre-run for 12 to $16 \mathrm{~h}$ with $1 \mathrm{X}$ TBE buffer ( $45 \mathrm{mM}$ Tris-borate, $1 \mathrm{mM}$ EDTA, $\mathrm{pH} \mathrm{8.0)}$ ) and photographed in UVP Bio-Imaging System using a UV transilluminator.

\section{RESULTS}

\section{BmMNPV infection symptomology}

Analysis of fifth-instar commercial B. mori hybrids, experimentally inoculated with BmMNPV, revealed several characteristic symptoms caused by baculovirus disease, which were consistently repeated in all experiments and which were absent in control larvae.

Appetite decrease and loss were observed in larvae between the third and fourth dpi (Table 1). Gradual change in tegument color, from white in silkworm control to white-yellow, indicated the disease's first external sign. Change occurred on the fourth dpi in the Co.B group and on the fifth dpi in the Co.A group. Swelling of intersegmentary membranes was visible between the fifth and seventh dpi in Co.A, and between the fourth and sixth dpi in Co.B.

\begin{tabular}{|c|c|c|}
\hline \multicolumn{2}{|c|}{ Days after inoculation } & \multirow[t]{2}{*}{ Symptoms } \\
\hline Co.A & Co.B & \\
\hline 4 & 3 & - appetite decrease \\
\hline 5 & 4 & - change in color of the skin (white to white-yellow) \\
\hline \multirow{2}{*}{$5-7$} & $4-6$ & - swelling of the intersegmentary membranes \\
\hline & & $\begin{array}{l}\text { - behavior changed, silkworms show negative geotropism } \\
\text { and random movement in the culture box } \\
\text { - trail milky-like liquid }\end{array}$ \\
\hline 5 & 5 & - beginning of the death of silkworms \\
\hline $5-8$ & $5-8$ & - fragility and rupture of the tegument \\
\hline $9-11$ & $9-11$ & - beginning of cocoon construction \\
\hline
\end{tabular}

Control silkworm always moved toward feed and remained there while feeding or resting, whereas inoculated larvae revealed a random movement marked by bluish-white liquid traces. The larvae sought the highest points of the breeding box, revealing an obvious negative geotropism. Pronounced tegument fragility was reported in the final stage of infection, between the sixth and eighth dpi. Moreover, in some cases, the tegument was ruptured with the spilling of a bluish-white hemolymph.

The death rate was $62 \%$ in the Co.A group and $76 \%$ in the Co.B group in the larval stage (Figure 1) and happened between the fifth and the eighth dpi. Some died hanging upside down, fixed to the highest points of the breeding box by their false abdominal feet. In most cases, there was a spontaneous rupture of the tegument at death, with the spilling of a whitish 
liquid from the body. Infected larvae had a softly, white-yellow body that darkened as time passed, becoming totally black $24 \mathrm{~h}$ after death.

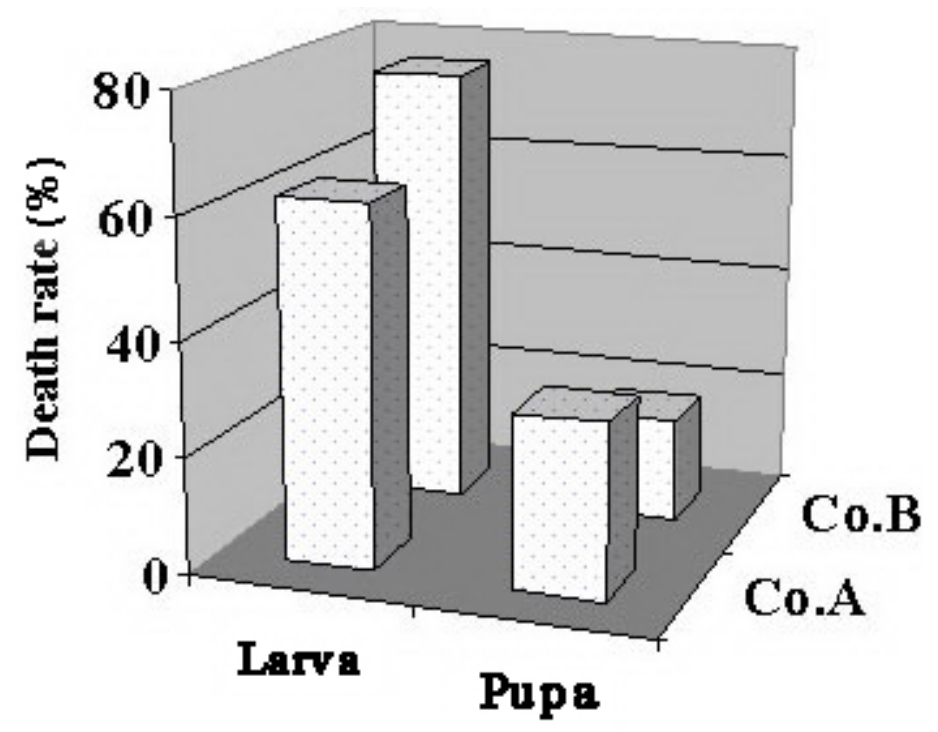

Figure 1. Bombyx mori multiple nucleopolyhedrovirus inoculation bioassay. Analysis involved commercial hybrids of two sericulture companies, Co.A and Co.B, which were inoculated after ecdysis at the 5 th instar by viral suspension $\left(1.4 \times 10^{6}\right.$ polyhedral occlusion bodies $\left./ \mathrm{mL}\right)$. Symptoms were observed daily (Table 1) and frequency of dead rate was observed in larva and pupa stages. Control silkworms showed a death rate of 5\% only in larval stage (data not shown).

While the larvae of the control group of the two companies started making cocoons on the seventh day, $38 \%$ of the experimentally inoculated silkworms of the Co.A group and $24 \%$ of the Co.B group started making cocoons after this time, showing a prolongation of the larval stage. Cocoons produced by the two inoculated groups revealed flaws and internal blemishes. Some silkworm died soon afterwards and did not finish the cocoon. Emergence of moths occurred in $8 \%$ of cocoons in the Co.A group, whereas this occurred in only $6 \%$ of cocoons in the Co.B group. Emergence occurred at approximately fifteen days after the start of cocoon building. Emergent moths were apparently normal with a complete life cycle. Control silkworms showed a death rate of the $5 \%$ only in larval stage (data not shown).

\section{Analysis of markers associated with susceptibility and resistance to BmMNPV}

Genomic DNA of commercial hybrids Co.A and Co.B was extracted from silk glands of five control and five experimental specimens at the seventh dpi to detect specific RAPD bands to susceptibility and/or resistance to BmNPV, as described by Yao et al. (2003). Primer OPY-11 was employed to amplify a polymorphic fragment of $\sim 350 \mathrm{bp}$, described as being associated with the silkworm's susceptibility. This fragment was detected in all specimens analyzed here (Figure 2A and B, OPY-11(S). Yao et al. (2003) also reported the presence of an RAPD polymorphic fragment of $\sim 700 \mathrm{bp}$ from primer OPA-18, which is linked to B. mori's resistance to BmNPV, amplified in 
the parental strain and confirmed by analysis of several generations through backcrossing. The analysis carried out on our specimens failed to show amplification of this described fragment. When our research team recently analyzed specimens of $B$. mori from parental strains, this fragment was also not detected (Zanatta, 2006). However, a polymorphic band of $\sim 800 \mathrm{bp}$, which is not always detected in different strains, was associated with resistance to BmMNPV (Zanatta, 2006). A faint fragment with $\sim 800 \mathrm{bp}$ was observed in all specimens when hybrids of both companies were analyzed (Figure 3A and B, OPA-18(R). However, the bioassay shows that 92\% (Co.A) and 94\% (Co.B) of the silkworms analyzed here were susceptible to BmMNPV and the occurrence of the $\sim 800$-bp fragment alone is not sufficient for the establishment of resistance. An unexpected result was the detection of an additional fragment only in the amplified DNA of the specimens experimentally inoculated with BmMNPV (Figure 3A and B, BmMNPV (480 bp). Recently, this fragment was cloned and sequenced by our research team (Pereira et al., 2008). These results showed that this sequence belongs to ORF 14 of the BmNPV, whose product is probably related to a protein of the viral envelope.
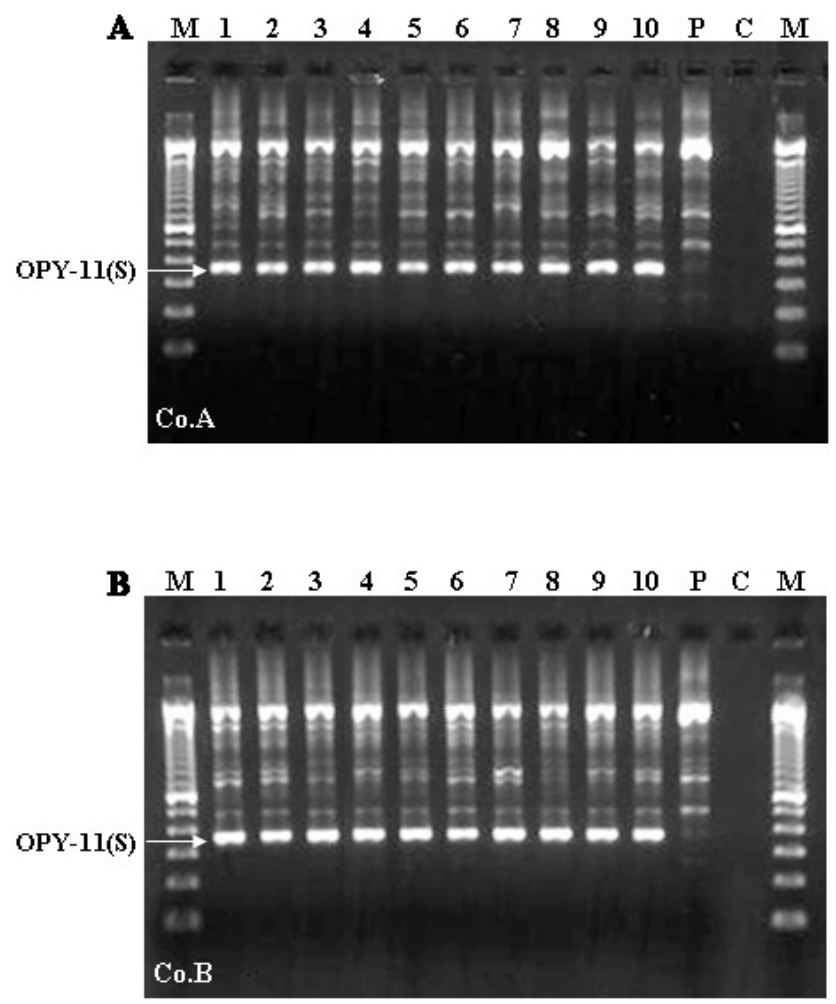

Figure 2. Random amplified polymorphic DNA profile produced by OPY-11 primer. Genomic DNA from silk glands of the five control (lanes 1-5) and five inoculated (lanes 6-10) by Bombyx mori multiple nucleopolyhedrovirus (BmMNPV) specimens from commercial B. mori hybrids of Co.A and Co.B was purified and amplified with OPY11 primer (details in Material and Methods). A fragment with $\sim 350 \mathrm{bp}$, associated with susceptibility to BmMNPV was detected in all specimens, OPY-11(S). $\mathrm{P}=$ B. mori parental strain (Chinese matrix) was used as negative control for this polymorphic fragment; $\mathrm{C}=$ negative control for amplification reaction on $1.5 \%$ agarose gel. $\mathrm{M}=100-\mathrm{bp}$ ladder molecular weight marker (Invitrogen). 

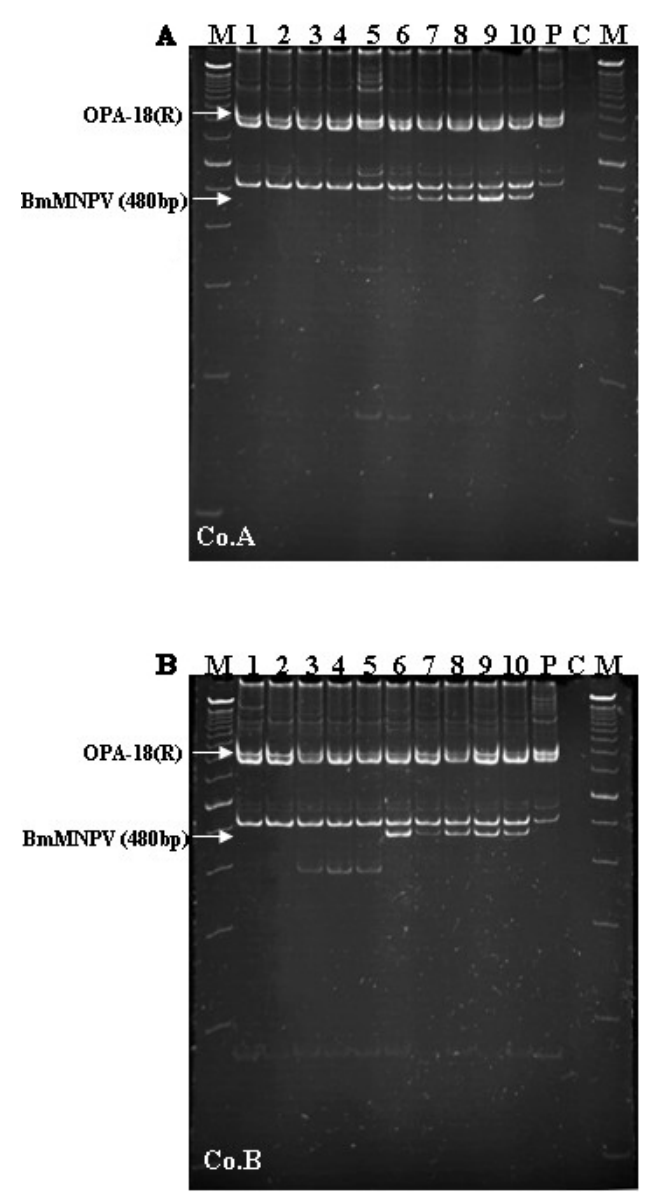

Figure 3. Random amplified polymorphic DNA profile produced by OPA-18 primer. Genomic DNA of silk glands of the five control (lanes 1-5) and five inoculated (lanes 6-10) by Bombyx mori multiple nucleopolyhedrovirus (BmMNPV) specimens from commercial B. mori hybrids of Co.A and Co.B was purified and amplified with OPA18 primer (details in Material and Methods). A fragment with $\sim 800 \mathrm{bp}$, associated with resistance to BmMNPV was detected in all specimens, OPA-18(R). $\mathrm{P}=$ B. mori parental strain (Chinese matrix) was used as positive control for this polymorphic fragment; $\mathrm{C}=$ negative control for amplification reaction on $6 \%$ polyacrylamide gel. $\mathrm{M}=100$-bp ladder molecular weight marker (Invitrogen).

\section{DISCUSSION}

Symptomologic analysis of B. mori commercial hybrids demonstrated a classical NPV-caused infection (Granados and Williams, 1986; Adams and McClintock, 1991; Brancalhão, 2002; Rahman and Gopinathan, 2004). During all its stages of development (egg, larva, pupa, and moth), B. mori is susceptible to NPV infection (Goldsmith et al., 2005). When infection occurs at the first instar, the larvae may die within 1 to 2 dpi; after the third instar, 
symptoms fail to appear for several days after the ingestion of pathogen (Brancalhão, 2002; Rahman and Gopinathan, 2004).

There are many explanations for such time variations in symptom manifestation, or rather, the development phase in which larvae are incubated, the amount of virus ingested and its virulence (Granados and Williams, 1986; Hanada and Watanabe, 1986), and insect strains, which may be more susceptible to NPV (Ponnuvel et al., 2003; Nakazawa et al., 2004).

As reported in the present study, the first signs of metabolic dysfunction are loss of appetite and changes in tegument color and in behavior of larvae (Adams and McClintock, 1991; Bilimoria, 1991; Torquato et al., 2006). Similar to reports by other authors (Hanada and Watanabe, 1986; Brancalhão et al., 2002; Brancalhão and Ribeiro, 2003), these experiments showed that infected larvae seek the highest places in breeding boxes and thus reveal negative geotropism.

Changes in tegument coloring of commercial B. mori hybrids are due to infection and lysis of susceptible tissues, mainly the fatty ones. In fact, these are the NPV's preferential targets, as many authors have reported (Bilimoria, 1991; Adams and McClintock, 1991; Brancalhão et al., 2002; Brancalhão and Ribeiro, 2003).

Swelling of intersegment membranes and tegumental fragility, with frequent ruptures, are common features in NPV baculovirus-caused infections (Adams and McClintock, 1991; Brancalhão et al., 2002; Brancalhão and Ribeiro, 2003; Torquato et al., 2006). Ohkawa et al. (1994) and Hawtin et al. (1997) state that probably cathepsin and chitinase, present in the genome of NPVs, may be the enzymes that cause degradation of the insect's cuticle in the later stages of infection. Hanada and Watanabe (1986) and Adams and McClintock (1991) show that histolysis produces a hemolymph rich in polyhedra, cell remains and lipids.

Prolongation of the larval stage reported in BmMNPV-inoculated hybrids may be due to the viral gene EGT (ecdysteroid UDP-glycosyltransferase), which decomposes ecdysone (molting hormone) and thus an increase in the life of the larva (O'Reilly and Miller, 1990). As expected, prolongation of larval stage causes the virus to infect a larger number of NPVsusceptible cells and tissues with an increase in viral progenies (Tanada and Kaya, 1993).

Biological assays showed that the geographic BmMNPV isolate is highly virulent to commercial hybrids distributed in Brazil for sale. This fact is surmised from the high mortality rate of larvae from both companies. It should also be emphasized that infected silkworms are a potential source of virus. Due to the quantity of polyhedrons produced (Granados and Williams, 1986; Sengupta et al., 1990; Bilimoria, 1991), prevention measures are of importance to avoid transmission and spread in B. mori breeding houses and in mulberry leaves (Brancalhão, 2002).

A previous study of $B$. mori parental strains carried out in our laboratory showed that only Japanese strains amplify an $\sim 350$-bp band associated with NPV susceptibility (Zanatta, 2006). Although they are the largest silk producers, more than the Chinese, Japanese strains are less resistant to several field factors, which include resistance to viral diseases. Since commercial hybrids are derived from crossings between Japanese and Chinese strains, the detection of this fragment in hybrid specimens is expected.

The $\sim 800$-bp fragment, associated with baculovirus-resistance, has been observed in all ten hybrid specimens analyzed in the present study. The results may indicate that absence of these susceptibility/resistance markers is less than $10 \%$ of the commercial hybrid population currently distributed in Brazil.

Yao et al. (2003) reported that absence frequencies of $12.5 \%$ for the susceptible-associated band ( $\sim 350 \mathrm{bp}$ ) and of $17 \%$ for the resistance-associated band ( $\sim 700 \mathrm{bp})$ were determined 
in the case of F2 individuals, product of crossings of parental strains formed by highly resistant specimen, strain NB, and susceptible to BmNPV (strain 306). Since commercial hybrids were obtained by crossing of parental strains whose origin is a classified material by sericulture companies, frequency (less than 10\%) reported in the present analysis may be true for the population studied. When 16 parental strains were analyzed, our research group estimated the frequency absence for the susceptibility band at 6 and 19\% for the resistance one (Zanatta, 2006).

In conclusion, the analysis of hybrid silkworms showed fragments identified as susceptibility/resistance molecular markers. Commercial hybrids distributed in Brazil are susceptible to the geographic BmMNPV isolate with higher death rate during the larval stage, without any difference between the hybrids from the two companies. The additional $\sim 480$-bp fragment, identified with the OPA-18 primer in RAPD amplification conditions, could be used as a molecular marker in the diagnosis of nucleopolyhedrovirus-caused infection.

\section{ACKNOWLEDGMENTS}

The authors would like to thank the sericulture companies of the State of Paraná for providing the Bombyx mori hybrid silkworms. Research supported by grants from the Secretaria de Estado da Ciência, Tecnologia e Ensino Superior, SETI, FUNDO PARANA, Fundação Araucária, Santander-Banespa Prize for Science and Innovation 2006 and COMCAP/ UEM laboratory facilities.

\section{REFERENCES}

Abe H, Shimada T, Tsuji T, Yokoyama T, et al. (1995). Identification of random amplified polymorphic DNA linked to the densonucleosis virus type-1 susceptible gene of the silkworm, Bombyx mori. J. Seric. Sci. Jpn. 64: 262-264.

Abe H, Sugasaki T, Kanehara M, Shimada T, et al. (2000). Identification and genetic mapping of RAPD markers linked to the densonucleosis refractoriness gene, nsd-2, in the silkworm, Bombyx mori. Genes Genet. Syst. 75: 93-96.

Adams JR and McClintock JT (1991). Baculoviridae Nuclear Polyhedrosis viruses. Part 1. Nuclear Polyhedrosis Viruses of Insects. In: Atlas of Invertebrate Viruses (Adams JR and Bonami JR, eds.). CRC Press, Florida, 89-180.

Barrett JW, Brownwright AJ, Primavera MJ and Palli SR (1998). Studies of the nucleopolyhedrovirus infection process in insects by using the green fluorescence protein as a reporter. J. Virol. 72: 3377-3382.

Bilimoria SL (1991). The Biology of Nuclear Polyhedrosis Viruses. In: Viruses of Invertebrates (Kurstak E, ed.). Marcel Dekker, New York, 1-72.

Brancalhão RMC (2002). Vírus entomopatogênicos no bicho-da-seda. Taxonomia e citopatologia causada por nucleopolyhedrovirus em células de Bombyx mori. Biotec. Cienc. Desenvol. 24: 54-58.

Brancalhão RMC and Ribeiro LFC (2003). Citopatologia da infecção causada por BmNPV no tegumento de Bombyx mori L., 1758 (Lepidoptera: Bombycidae). Arq. Ciên. Vet. Zool. 6: 21-27.

Brancalhão RMC, Souza VBV and Fortes JC (2000). A simplified methodology to detect nucleopolyhedrovirus in Bombyx mori L., 1758 (Lepidoptera: Bombycidae). Arq. Ins. Biol. 67: 89-92.

Brancalhão RMC, Souza VBV and Soares MAM (2002). Infecção causada por nucleopolyhedrovirus nas células gordurosas de Bombyx mori L., 1758 (Lepidoptera: Bombycidae). Arq. Inst. Biol. 69: 57-63.

Fernandez MA, Ciferri RR, Patussi EV, Pereira MF, et al. (2005). A utilização da biotecnologia na sericultura brasileira. Biotec. Cienc. Desenvol. 35: 56-61.

Goldsmith MR, Shimada T and Abe H (2005). The genetics and genomics of the silkworm, Bombyx mori. Annu. Rev. Entomol. 50: 71-100.

Granados RR and Williams K (1986). In vivo Infection and Replication of Baculovirus. In: The Biology of Baculoviruses (Granados RR and Federici BA, eds.). CRC Press, Florida, 89-108.

Hanada Y and Watanabe JK (1986). Manual de Criação do Bicho-da-Seda. COCAMAR, Curutiba.

Hawtin RE, Zarkowska T, Arnold K, Thomas CJ, et al. (1997). Liquefaction of Autographa californica nucleopolyhedrovirusinfected insects is dependent on the integrity of virus-encoded chitinase and cathepsin genes. Virology 238: 243-253. 
Monesi N, Jacobs-Lorena M and Paco-Larson ML (1998). The DNA puff gene BhC4-1 of Bradysia hygida is specifically transcribed in early prepupal salivary glands of Drosophila melanogaster. Chromosoma 107: 559-569.

Nakazawa H, Tsuneishi E, Ponnuvel KM, Furukawa S, et al. (2004). Antiviral activity of a serine protease from the digestive juice of Bombyx mori larvae against nucleopolyhedrovirus. Virology 321: 154-162.

O’Reilly DR and Miller LK (1990). Regulation of expression of a baculovirus ecdysteroid UDPglucosyltransferase gene. J. Virol. 64: 1321-1328.

Ohkawa T, Majima K and Maeda S (1994). A cysteine protease encoded by the baculovirus Bombyx mori nuclear polyhedrosis virus. J. Virol. 68: 6619-6625.

Pereira EP, Conte H, Ribeiro LF, Zanatta DB, et al. (2008). Cytopathological process by multiple nucleopolyhedrovirus in the testis of Bombyx mori L., 1758 (Lepidoptera: Bombycidae). J. Invertebr. Pathol. 99: 1-7.

Ponnuvel KM, Nakazawa H, Furukawa S, Asaoka A, et al. (2003). A lipase isolated from the silkworm Bombyx mori shows antiviral activity against nucleopolyhedrovirus. J. Virol. 77: 10725-10729.

Rahman MM and Gopinathan KP (2004). Systemic and in vitro infection process of Bombyx mori nucleopolyhedrovirus. Virus Res. 101: 109-118.

Sengupta K, Kumar P, Baig M and Govindaia H (1990). Handbook on Pest and Disease Control of Mulberry and Silkworm. UNESCAP (United Nations Economic and Social Commission for Asia and the Pacific), Bangkok.

Tanada Y and Kaya HK (1993). Insect Pathology. Chapter 6. In: DNA-Viral Infections: Baculoviridae. Academic Press, San Diego, 171-244.

Torquato EF, Neto MH and Brancalhao RM (2006). Nucleopolyhedrovirus infected central nervous system cells of Bombyx mori (L.) (Lepidoptera: Bombycidae). Neotrop. Entomol. 35: 70-74.

Williams JG, Kubelik AR, Livak KJ, Rafalski JA, et al. (1990). DNA polymorphisms amplified by arbitrary primers are useful as genetic markers. Nucleic Acids Res. 18: 6531-6535.

Yao Q, Lim W, Wang Y, Wang WB, et al. (2003). Screening of molecular markers for NPV resistance in Bombyx mori L. (Lep., Bombycidae). J. Appl. Entomol. 127: 134-136.

Zanatta DB (2006). Identificação de marcadores RAPD para polimorfismo, resistência e suscetibilidade em linhagens de Bombyx mori. Master's thesis, Universidade Estadual de Maringá, Maringá.

Zhou M, Sun X, Sun X, Vlak JM, et al. (2005). Horizontal and vertical transmission of wild-type and recombinant Helicoverpa armigera single-nucleocapsid nucleopolyhedrovirus. J. Invertebr. Pathol. 89: 165-175. 